\title{
Laparoscopy versus laparotomy for the management of endometrial carcinoma in morbidly obese patients: a prospective study
}

\author{
Özgür Bige ${ }^{1}$, Ahmet Demir ${ }^{2}$, Bahadır Saatli ${ }^{3}$, Meral Koyuncuoğlu ${ }^{4}$, Uğur Saygılı ${ }^{3}$ \\ ${ }^{1}$ Department of Obstetrics and Gynecology, Tekirdağ Star Medica Hospital, Tekirdağ, Turkey \\ ${ }^{2}$ Clinic of Obstetrics and Gynecology, Elazığ Training and Research Hospital, Elazı̆̆, Turkey \\ ${ }^{3}$ Department of Obstetrics and Gynecology, Dokuz Eylül University Faculty of Medicine, İzmir, Turkey \\ ${ }^{4}$ Department of Pathology, Dokuz Eylül University Faculty of Medicine, Izmir, Turkey
}

\section{Abstract}

Objective: To compare the results of total laparoscopic hysterectomy and total abdominal hysterectomy in morbidly obese women with early stage endometrial cancer.

Material and Methods: This prospective study was conducted on 140 morbidly obese women with body mass indices $\geq 35 \mathrm{~kg} / \mathrm{m}^{2}$ and presenting with clinical stage 1 endometrial cancer. The patients underwent total laparoscopic hysterectomy $(n=70)$ or total abdominal hysterectomy $(\mathrm{n}=70)$, bilateral salpingo-oophorectomy, pelvic lymphadenectomy, and peritoneal washing. Age, parity, menopausal status, weight, height, medical problems, history of previous laparotomy, surgical procedure, operative time, estimated amount of blood loss, preoperative hematocrit, postoperative hematocrit, operative complications, conversion to laparotomy, need for intraoperative or postoperative blood transfusion, intraoperative and postoperative complications, secondary surgery, tumor stage, grade, histology, number of recovered lymph nodes, and visual pain scores of the patients were recorded.

Results: Postoperative complications were significantly higher in the laparotomy group. Hospital stay in the laparoscopy group was significantly lower than that in the laparotomy group. The visual pain scores were significantly higher in the laparotomy group on the first, second, and third postoperative days and on the day of discharge from the hospital. Resuming activity took a significantly longer time in the laparotomy group (34.70 days) than in the laparoscopic group (17.89 days).

Conclusion: With the availability of skilled endoscopic surgeons, most obese women with early stage endometrial cancer can be safely managed by performing laparoscopy with an excellent surgical outcome, shorter hospitalization, less postoperative pain, and faster resumption of full activity. (J Turk Ger Gynecol Assoc 2015; 16: 164-9)

Keywords: Laparoscopy, endometrial carcinoma, morbidly obese patients

Received: 09 February, 2015

Accepted: 19 April, 2015

Available Online Date: 14 July, 2015

\section{Introduction}

Endometrial cancer (EC) is the most common gynecologic malignancy among women in Turkey with an incidence of 8.4 cases per 100.000 (1). The standard modality of management of early EC is surgery via laparotomy. Laparoscopic surgery for EC was first reported by Childers and Surwit in 1992 (2). Recently, diverse studies have demonstrated favorable outcomes of laparoscopic surgery for EC.

Most patients with EC are obese (3). The risk of diabetes, cardiovascular disease, and death due to EC is 6.25 times higher in morbidly obese patients (4). Obesity is one of the common public health problems in Turkey, particularly among women. The Turkish population has a higher rate of obesity than European countries; however, the rate is similar with the United States (5). Obesity and other medical conditions often complicate the surgery, thereby increasing the morbidity and mortality rates of the disease. Obesity makes the laparoscopic approach more difficult $(6,7)$. However, it has been shown that obese patients are benefitted more from laparoscopy. Laparoscopic staging of EC in obese or morbidly obese patients results in fewer operative complications and faster recovery (8-11).

The aim of this study was to compare the laparoscopic approach with laparotomy in morbidly obese Turkish women with early stage EC women with similar clinical characteristics.

\section{Material and Methods}

This prospective study was conducted at the Department of Obstetrics and Gynecology, Dokuz Eylül University School of Medicine, İzmir, Turkey from January 2005 to July 2012. The same surgical team performed the surgeries (US, OB, BS). The subjects were morbidly obese clinical stage $1 \mathrm{EC}$ women, with body mass indices (BMIs) $\geq 35 \mathrm{~kg} / \mathrm{m}^{2}$. The patients 
who met the inclusion criteria were offered total laparoscopic hysterectomy (TLH), pelvic lymphadenectomy, and peritoneal washing. The patients who refused laparoscopic management underwent laparotomy and were included in the laparotomy group. Patients who previously underwent retroperitoneal surgery and radiation therapy to the lower abdominal region and had severe cardiopulmonary disease, severe orthopedic problems, enlarged uterus preventing vaginal removal, intraperitoneal disease, cervical involvement, and contraindications to laparoscopy were excluded from the study.

Obesity is classified according to the World Health Organization as class I for a BMI between 30 and $34.9 \mathrm{~kg} / \mathrm{m}^{2}$, class II for a BMI between 35 and $39.9 \mathrm{~kg} / \mathrm{m}^{2}$, and class III for a BMI $\geq 40 \mathrm{~kg} / \mathrm{m}^{2}$. The patients with a BMI $\geq 35 \mathrm{~kg} / \mathrm{m}^{2}$ were allowed to participate in the study. Informed consent for each patient and approval of the institutional ethics committee were obtained.

All patients underwent bowel preparation preoperatively. Antibiotics prophylaxis in the form of $1000 \mathrm{mg}$ Cefazoline (Cefozin, Bilim Ilaç, İstanbul, Turkey) was administered before the skin incision. A low-molecular-weight heparin, Enoxaparin Sodium $40 \mathrm{mg}$ (Clexane, Sanofi Aventis, İstanbul, Turkey), was injected subcutaneously for antithrombotic prophylaxis starting from $12 \mathrm{~h}$ before the surgery and continued for 14 days postoperatively. As surgical staging peritoneal washing, TLH or total abdominal hysterectomy, bilateral salpingo-oophorectomy and bilateral pelvic and/or paraaortic lymphadenectomy were performed.

In addition to the general characteristics of the patients surgical, procedure, operative time (OT), estimated amount of blood loss (EBL), hematocrit levels, operative complications, conversion to laparotomy, need of blood transfusion, secondary surgery, tumor stage, grade, histology, number of recovered lymph nodes, and visual pain scores of the patients were recorded.

The time spent from the entry of the Veress needle to the last suture on skin incision was defined as OT. The time spent for paraaortic lymphadenectomy was calculated separately. Estimating the amount of irrigated fluid and the weight of the swabs helped to calculate EBL. The hemoglobin level lower than $8 \mathrm{~g} / \mathrm{dL}$ or symptomatic anemia was accepted as indications for erythrocyte suspension transfusion. Ureteral, bowel, bladder, vascular injuries, bleeding requiring blood transfusion, and abdominal wall bleeding were defined as intraoperative complications. Analgesia was controlled by Tradamol (Contramal, Abdi İbrahim, İstanbul, Turkey), and Tenoxicam (Tilcotil, Deva, İstanbul, Turkey) was used to relieve the postoperative pain. The time interval between the surgical intervention and discharge of the patient from the hospital was described as the length of hospital stay. Deep vein thrombosis, pulmonary thromboembolism, ileus, gastrointestinal system bleeding, cellulitis, wound infection or infection requiring antibiotherapy, port site herniation, and evisceration or eventration occurring within 30 days after surgery were determined as postoperative complications. The patients recovered within 3- and 6-month time periods for the first and second years after surgical intervention, respectively.

\section{Surgical intervention}

Laparotomy was performed according to the International Federation of Gynecology and Obstetrics (FIGO) staging system defined in 1988 (12). The TLH procedures were performed according to the classification system described by Garry et al. (13). A closed entry technique with the Veress needle and carbon dioxide gas insufflation was used. Following the establishment of pneumoperitoneum, a camera was placed through the umbilicus. Totally, two $10 \mathrm{~mm}$ and two $5 \mathrm{~mm}$ trocars were inserted into the abdomen. A laparoscopic sealer/divider instrument, $10 \mathrm{~mm}$ LigaSure AtlasTM (Valleylab, Covidien, Minneapolis, United States), was used in all procedures. Round ligaments were divided and retroperitoneal spaces were established bilaterally. The uterine arteries were first identified and ligated. Then, the infundibulopelvic ligaments were transsected by LigaSure. Following dissection of the anterior and posterior peritoneum, uterosacral and cardinal ligaments were divided. Vaginal fornixes were delineated and circular colpotomy was performed using unipolar hook cautery. All the specimens were retrieved from the vagina. The vaginal cuff was closed with intracorporal 1/0 Polyglycolide-co-Lactide sutures (Pegelak, Doğsan, Trabzon, Turkey).

All patients underwent pelvic lymph node dissection regardless of the grade of the disease. The paraaortic lymphadenectomy was performed in the case of the surgical stage of IB-IV for all grades or in a case of high-risk histology such as clear cell or papillary serous adenocarcinoma. The external iliac artery and vein, the internal iliac artery and vein, the iliac bifurcation, and the obturator nerve were clearly visible at the end of the pelvic lymphadenectomy. Omentectomy was performed in the cases of high-risk histology. Frozen section analysis was performed in all cases. During paraffin section analysis, tumor deposits and positive lymph nodes were discriminated.

A comparison of patient characteristics between the groups was performed using a two-sample $t$ test, Chi square, and Fisher's exact test. The total sample size $(n=140)$ resulted in a power of $80 \%$ with an $\alpha$ error of 0.05 . All the statistical analyses were performed using the Statistics Software Package for the Social Sciences (SPSS) version 15.0 (SPSS Inc, Chicago, Illinois, United States). Two-tailed p values $<0.05$ were considered as statistically significant.

\section{Results}

Totally, 140 morbidly obese women with clinical early stage EC who met the inclusion criteria were included in the study. The study participants were allocated to either the laparoscopy group $(n=70)$ or the laparotomy group $(n=70)$.

Of 70 patients, six laparoscopic procedures converted to laparotomy. The conversion rate was 6/70 (8.6\%). Advanced stage disease $(n=3)$, vascular injury $(n=1)$, dense adhesions $(n=1)$, and intestinal injury $(n=1)$ were considered as underlying causes of conversion to laparotomy. These patients were not excluded from the laparoscopy group in further analysis.

There were no significant differences in age, BMI, comorbidities, previous laparotomy, and operative procedures (Table 1). Table 2 illustrates the International Federation of Gynecology and Obstetrics (FIGO) stages, histologies, and grades of the tumors that were similar among women in both groups. There were significant differences between the two groups with respect 
Table 1. Patient characteristics

\begin{tabular}{|c|c|c|c|}
\hline & TLH $(n=70)$ & TAH $(n=70)$ & $\mathbf{p}$ \\
\hline Age (years)* & $55.56 \pm 10.62$ & $56.24 \pm 10.55$ & NS \\
\hline $\begin{array}{l}\text { Body mass index } \\
\left(\mathrm{BMI} ; \mathrm{kg} / \mathrm{m}^{2}\right)^{*}\end{array}$ & $44.49 \pm 6.99$ & $45.90 \pm 7.22$ & NS \\
\hline \multicolumn{4}{|l|}{ Comorbidities** } \\
\hline One & $23(32.9)$ & $20(28.6)$ & NS \\
\hline$\geq$ Two & $42(60.0)$ & $44(62.9)$ & NS \\
\hline Previous Laparotomy** & $24(34.3)$ & $19(27.1)$ & NS \\
\hline \multicolumn{4}{|l|}{ Procedure** } \\
\hline $\begin{array}{l}\text { Hysterectomy + } \\
\text { PLND }\end{array}$ & $62(88.57 \%)$ & $61(87.14 \%)$ & NS \\
\hline $\begin{array}{l}\text { Hysterectomy + } \\
\text { PLND+PALND }\end{array}$ & $8(11.43 \%)$ & $9(12.86 \%)$ & NS \\
\hline \multicolumn{4}{|c|}{$\begin{array}{l}\text { *mean } \pm \text { SD, ** number, } \% \\
\text { TLH: total laparoscopic hysterectomy; TAH: total abdominal hyster- } \\
\text { ectomy; PLND: pelvic lymph node dissection; PALND: paraaortic } \\
\text { lymph node dissection; NS: nonsignificant }\end{array}$} \\
\hline
\end{tabular}

Table 2. Stage and grade of the operations

\begin{tabular}{|c|c|c|c|}
\hline & TLH $(n=70)$ & TAH $(n=70)$ & $\mathbf{p}$ \\
\hline \multicolumn{4}{|l|}{ FIGO Stage } \\
\hline I-II & 67 & 68 & \\
\hline III-IV & 3 & 2 & \\
\hline \multicolumn{4}{|l|}{ Histology } \\
\hline Endometrioid & 64 & 63 & NS \\
\hline Papillary serous & 2 & 3 & $\mathrm{NS}$ \\
\hline Clear cell & 2 & 2 & NS \\
\hline $\begin{array}{l}\text { Endometrial stromal } \\
\text { sarcoma }\end{array}$ & 1 & 0 & NS \\
\hline $\begin{array}{l}\text { Mixed mullerian } \\
\text { tumor }\end{array}$ & 1 & 2 & NS \\
\hline \multicolumn{4}{|l|}{ Grade (n, \%) } \\
\hline 1 & $36(51.4 \%)$ & $40(57.1 \%)$ & NS \\
\hline 2 & $26(37.14 \%)$ & $22(31.4 \%)$ & NS \\
\hline 3 & $8(14.28 \%)$ & $8(11.4 \%)$ & NS \\
\hline
\end{tabular}

TLH: total laparoscopic hysterectomy; TAH: total abdominal hysterectomy; FIGO: international federation of gynecology and obstetrics; NS: nonsignificant

to OT and EBL. The mean OT was $155.03 \pm 37.68$ (124-340) min with EBL of $561.86 \pm 341.55(254-1800 \mathrm{~mL})$ and $185.94 \pm 30.26$ (130-245) min with EBL of $438.29 \pm 271.97(290-1250 \mathrm{~mL})$ in the laparoscopy and laparotomy groups, respectively. There were no significant differences between the number of intraoperative and postoperative blood transfusions and the number of lymph nodes collected (Table 3 ). The complication rates are illustrated in Table 4. There were no significant differences in the rates of the intraoperative complications of both groups. However, postoperative complications were significantly higher in the laparotomy group.
Table 3. Characteristics of the operations

\begin{tabular}{|l|c|c|c|}
\hline & $\begin{array}{c}\text { TLH } \\
(\mathbf{n = 7 0 )}\end{array}$ & $\begin{array}{c}\text { TAH } \\
(\mathbf{n = 7 0 )}\end{array}$ & $\mathbf{p}$ \\
\hline $\begin{array}{l}\text { Operating room } \\
\text { time (min)* }\end{array}$ & $155.03 \pm 37.68$ & $185.94 \pm 30.26$ & $<0.001$ \\
\hline $\begin{array}{l}\text { Estimated amount } \\
\text { of blood loss (mL)* }\end{array}$ & $561.86 \pm 341.55$ & $438.29 \pm 271.97$ & $<0.05$ \\
\hline $\begin{array}{l}\text { Intraoperative } \\
\text { blood transfusion** }\end{array}$ & $12(17.1 \%)$ & $10(14.2 \%)$ & NS \\
\hline $\begin{array}{l}\text { Postoperative blood } \\
\text { transfusion** }\end{array}$ & $6(8.6 \%)$ & $7(10.0 \%)$ & NS \\
\hline Lymph node count* & $22.99 \pm 6.7$ & $23.53 \pm 7.11$ & NS \\
\hline $\begin{array}{l}\text { Pelvic + Common iliac } \\
\text { Paraaortic }\end{array}$ & $10.50 \pm 7.23$ & $14.88 \pm 5.8$ & NS \\
\hline $\begin{array}{l}\text { *mean } \pm \text { SD, **n (\%) } \\
\text { TLH: total laparoscopic hysterectomy; TAH: total abdominal hysterec- } \\
\text { tomy; NS: nonsignificant }\end{array}$ & & & \\
\hline
\end{tabular}

Table 4. Intra- and postoperative complications

\begin{tabular}{|l|c|c|c|}
\hline & $\begin{array}{c}\text { TLH } \\
(\mathbf{n}=\mathbf{7 0})\end{array}$ & $\begin{array}{c}\text { TAH } \\
(\mathbf{n = 7 0 )}\end{array}$ & $\mathbf{p}$ \\
\hline $\begin{array}{l}\text { Intraoperative complications } \\
\text { (n, \%) }\end{array}$ & $5(7.14 \%)$ & $1(1.43 \%)$ & \\
\hline $\begin{array}{l}\text { Vascular injury requiring } \\
\text { intervention }\end{array}$ & 1 & - & NS \\
\hline Bowel injury & 2 & - & \\
\hline Bladder injury & 1 & - & \\
\hline $\begin{array}{l}\text { Hematoma requiring } \\
\text { intervention }\end{array}$ & 1 & 1 & \\
\hline $\begin{array}{l}\text { Postoperative complications } \\
\text { (n, \%) }\end{array}$ & $8(11.4 \%)$ & $21(30.0 \%)$ & 0.01 \\
\hline Deep vein thrombosis & 0 & 1 & \\
\hline Post incisional or port-site hernia & 1 & 5 & \\
\hline Cellulitis & 1 & 4 & \\
\hline Wound infection & 0 & 3 & \\
\hline Wound dehiscence & 0 & 1 & \\
\hline Ileus & 1 & 2 & \\
\hline Ureterovaginal fistula & 0 & 1 & \\
\hline Acute renal failure & 1 & 0 & \\
\hline Intensive care admission & 3 & 4 & \\
\hline Re-laparotomy & 1 & 0 & \\
\hline $\begin{array}{l}\text { TLH: total laparoscopic hysterectomy; TAH: total abdominal hysterec- } \\
\text { tomy; NS: nonsignificant }\end{array}$ & & & \\
\hline
\end{tabular}

Of the four intraoperative complications that occurred in the laparoscopy group, one of them required further reoperation by laparotomy and the other required conversion to laparotomy. In the first case, there were dense adhesions, including omentum on the left pelvic side wall due to previous left oophorectomy. Partial omentectomy and adhesiolysis was performed. Acute abdomen developed on the $7^{\text {th }}$ postoperative day. Body temperature, C-reactive protein, and white blood cell levels were 
elevated. Sigmoid colon injury was detected after tomographic examination. Colostomy (Hartman) was performed on the same day. The patient started to experience pain on the left leg; hypotension and severe dyspnea developed on the $12^{\text {th }}$ postoperative day. Thrombus in the left external iliac vein and pelvic abscess were detected on ultrasonography. The patient was reoperated. Thrombolectomy and pelvic abscess drainage were performed. Unfortunately, massive internal bleeding developed in the patient $1 \mathrm{~h}$ later after completing the operation. A wide damage in the iliac artery was noticed after draining the hematoma. The iliac artery was ligated and femora-femoral bypass was performed. The patient was discharged from the hospital 35 days after the first operation. In the second case, a vascular injury that occurred during the laparoscopic nodal dissection required laparotomy, and bilateral internal iliac arteries were ligated to stop the bleeding.

Hospital stay in the laparoscopy group was significantly lower than that in the laparotomy group. To determine the level of pain or describe the discomfort of the patients, a visual pain scale was used. The visual pain scores were significantly higher in laparotomy group on the first, second, and third postoperative days and on the day of discharge from the hospital. Resuming activity means performing only light household chores. It took a significantly longer time for the laparotomy group (34.70 days) to perform such activities than the laparoscopic group (17.89 days). There was only one recurrence in the laparotomy group but none in the laparoscopic group. There was no occurrence of death intraoperatively and immediately after the operation. The mean follow-up periods were similar (31.14 vs. 34.80 months in the laparoscopy and laparotomy groups, respectively). The death rates were same in the two groups. In the laparotomy group, one patient died because of pelvic recurrence after 24 months postoperatively and one patient died because of cardiac reasons 61 months postoperatively. In the laparoscopy group, two patients died during the follow-up period. One was due to urosepsis and the other was due to acute pyelonephritis and secondary bacteraemia after 20 and 24 months of the follow-up period, respectively (Table 5). The 3-year progression-free survival for the laparoscopy group was $100 \%$ and $98.57 \%$ in the laparotomy group. The corresponding 3 -year overall survival rates were $97.14 \%$ and $98.57 \%$ in the laparoscopy and laparotomy groups, respectively.

\section{Discussion}

Obese women are at a risk for developing EC (14). They have greater surgical and anesthetic risks. The recovery and wound healing take a longer time (15). Laparoscopic surgery for EC in obese patients as an alternative to laparotomy has been the subject of many studies during the past 10 years, and it has been associated with fewer operative complications and more rapid recovery (8-11). However, the results of the trials comparing laparotomy with laparoscopy are indiscriminate because of the heterogeneity of the inclusion criteria, surgical techniques, and extent and rate of lymphadenectomy performed. Therefore, to prevent the selection bias, our study was performed only in one center by the same surgical team. All the participants under-
Table 5. Postoperative follow-up characteristics of the operations

\begin{tabular}{|l|c|c|c|}
\hline & $\begin{array}{c}\text { TLH } \\
(\mathbf{n}=70)\end{array}$ & $\begin{array}{c}\text { TAH } \\
(\mathbf{n = 7 0 )}\end{array}$ & p \\
\hline $\begin{array}{l}\text { Postoperative hospital stay } \\
\text { (days)* }\end{array}$ & $4.64 \pm 4.68$ & $10.36 \pm 5.69$ & $<0.001$ \\
\hline Postoperative pain (VAS)* & \multicolumn{3}{|l|}{} \\
\hline First day & $4.13 \pm 1.54$ & $6.60 \pm 1.23$ & $<0.001$ \\
\hline Second day & $2.80 \pm 0.94$ & $5.67 \pm 1.94$ & $<0.001$ \\
\hline Third day & $2.27 \pm 0.88$ & $4.66 \pm 1.97$ & $<0.001$ \\
\hline $\begin{array}{l}\text { At the time of discharge } \\
\text { from the hospital }\end{array}$ & $1.96 \pm 0.89$ & $4.41 \pm 2.17$ & $<0.001$ \\
\hline Resuming full activity* & $17.89 \pm 11.52$ & $34.70 \pm 18.21$ & $<0.001$ \\
\hline Recurrence** & 0 & $1(1.42 \%)$ & NS \\
\hline Death** & $2(2.86 \%)$ & $2(2.86 \%)$ & NS \\
\hline Follow-up period (months)* & $31.14 \pm 19.00$ & $34.80 \pm 16.55$ & NS \\
\hline $\begin{array}{l}\text { Progression-free survival** } \\
\text { (3 years) }\end{array}$ & $70(100 \%)$ & $69(98.57 \%)$ & NS \\
\hline Overall survival** (3 years) & $68(97.14 \%)$ & $69(98.57 \%)$ & NS \\
\hline $\begin{array}{l}\text { * mean } \pm \text { SD, ** n (\%) } \\
\text { TLH: total laparoscopic hysterectomy; TAH: total abdominal hysterec- } \\
\text { tomy; VAS: visual pain score; NS: nonsignificant }\end{array}$ & \\
\hline
\end{tabular}

went pelvic lymph node dissection systematically and were followed by the same clinicians postoperatively in the clinic and after being discharged from the hospital.

The current study shows a significantly shorter operating room time and higher EBL in the laparoscopy group. The increase in blood loss may be secondary to the frequent use of irrigation and suctioning, limited number of options to stop the bleeding, and reduced vision during laparoscopy. Although there was a significant difference in EBL, the rates of intraoperative and postoperative blood transfusions were not different.

The mean operating room time was significantly shorter in laparoscopic surgery, contrary to most reports published previously $(8,10,11,16)$. Faster entry into the abdomen via a closed establishment of the pneumoperitoneum in laparoscopic access and well-trained endoscopic surgeons are the main factors that shorten the OT in laparoscopic surgery. The entry and closure of the abdomen took quite a long time, which lengthens the OT in patients in the laparotomy group.

Lymph node count has been used as a marker for the quality of staging in EC. Therefore, lymphadenectomy is an important step in gynecologic oncology. There were conflicting evidences in the literature regarding lymph node counts (8-11). Tumor staging should be accurate. The interobserver variability can be seen among pathologists about the evaluation of positive lymph nodes and tumor deposits (17). In addition to interpathologist variations, BMI also influences the final lymph node count in EC staging (18). We performed complete pelvic lymphadenectomy to all patients to increase the strength of the study. To prevent interpathologist variations, frozen and paraffin section analyses were performed by the same pathologists who are experienced in the gynecologic oncology field. In the cur- 
rent study, the average lymph node counts are not statistically different according to the procedure performed.

Several studies have demonstrated that laparoscopy causes lesser complications than laparotomy in obese women $(7,8$, $16,19-24)$. In the current study, there was no significant difference between both the groups with respect to the incidence of operative complications. However, postoperative complications were significantly higher in the laparotomy group. The most common complications were post-incisional hernia, cellulitis, and wound infections. The wound complications were significantly lower in the laparoscopy group (2.85\% vs. $18.57 \%$, $\mathrm{p}=0.002$ ) than the laparotomy group because of a smaller wound size. Deep vein thrombosis, ileus, and intensive care admissions were also lower in the laparoscopy group.

The conversion rate to laparotomy changes between $7.5 \%$ and $36 \%$ and increases proportionally with BMI $(7,8,25)$. A higher conversion rate has been described in patients with a high BMI (23). The conversion rate was $8.6 \%$ in our study and consistent with the literature. Two of the four intraoperative complications in the laparoscopy group resulted in conversion to laparotomy. In the first case, a vascular injury that occurred during the laparoscopic nodal dissection required laparotomy, and the bilateral internal iliac arteries were ligated to stop the bleeding. In the second case, the ileum was injured during adhesiolysis because of a previous appendectomy. A linear incision was formed $4 \mathrm{~cm}$ in length, the injured region was resected, and end-to-end anastomosis was performed laparotomically. In the first case of other two intraoperative complications without conversion to laparotomy, the urinary bladder was injured and repaired laparoscopically. In the second case, the sigmoid colon and iliac artery injuries were detected postoperatively. Both patients also fully recovered and had no permanent damage. With respect to hospital stay, laparotomy in the obese patients prolongs hospital stay $(7,8,10,11,15,26-28)$. Similarly, in our study, there was a significant difference (5.2 vs. 12.8 days, $\mathrm{p}<0.001$ ) between women who underwent laparoscopy and those who underwent laparotomy. This difference mostly originated from the higher rate of postoperative complications in the laparotomy group.

We observed that patients managed by laparoscopy experience significantly less pain on the first, second, and third postoperative days and also on the day of discharge from the hospital. They resumed full activity sooner than the laparotomy group. The smaller incisions, absence of bowel manipulation, and less exposure during laparoscopy to air decreases the postoperative pain and ileus and allows early ambulation and early discharge from the hospital.

Only one case of recurrence has been detected after a 36-month follow-up period in a study cohort. Four patients died because of various reasons. In the laparoscopy group, two patients died because of urosepsis and acute pyelonephritis with secondary bacteraemia after 20 and 24 months of follow-up periods, respectively. Postoperatively, in the laparotomy group, two patients died because of pelvic recurrence and cardiac disease after 24 and 60 months after discharge, respectively. None of the patients died for reasons connected to the operation. There was no significant difference with respect to either the overall survival or progression-free survival between the laparoscopy group and the laparotomy group.

Our study is a prospective but not a randomized study. Some patients that should have been operated by the laparoscopic route according to randomization demanded to be operated by laparotomy. This is a limitation of our study. Recently, robotic surgery has been used in gynecologic cancers. A comparison of laparoscopic versus robotic surgery in morbidly obese EC patients may be the subject of future studies.

In conclusion, obese women are at a higher risk of developing EC. The type of surgical management of the disease in morbidly obese women affects the operative morbidity. With the availability of skilled endoscopic surgeons, a laparoscopic approach does not increase the intraoperative morbidity related to surgery and it has favorable surgical outcomes, shorter hospitalization, less postoperative pain, and faster resumption of full activity postoperatively.

Ethics Committee Approval: Ethics committee approval was received for this study from the Local Institutional ethics committee of Dokuz Eylül Üniversity Faculty of Medicine.

Informed Consent: Written informed consent was obtained from patients who participated in this study.

Peer-review: Externally peer-reviewed.

Author Contributions: Concept - Ö.B., A.D., U.S.; Design - Ö.B., A.D., B.S.; Supervision - Ö.B., B.S., U.S.; Resource - Ö.B., A.D., U.S.; Materials - Ö.B., A.D., M.K.; Data Collection and/or Processing - Ö.B., B.S., U.S.; Analysis and/or Interpretation - Ö.B., A.D., B.S.; Literature Search Ö.B., B.S., U.S.; Writing - Ö.B., A.D., U.S.; Critical Reviews - Ö.B., U.S., M.K.

Conflict of Interest: No conflict of interest was declared by the authors.

Financial Disclosure: The authors declared that this study has received no financial support.

\section{References}

1. 2004-2006 Cancer Incidences in Turkey. Avaliable from: http://kanser.gov.tr/folders/file/8iL-2006

2. Childers JM, Surwit EA. Combined laparoscopic and vaginal surgery for the management of two cases of stage I EC. Gynecol Oncol 1992; 45: 46-51.[CrossRef]

3. Reeves KW, Carter GC, Rodabough RJ, Lane D, McNeeley SG, Stefanick ML, Paskett ED. Obesity in relation to EC risk and disease characteristics in the Women's Health Initiative. Gynecol Oncol 2011; 121: 376-82. [CrossRef]

4. Calle EE, Rodriquez C, Walker-Thurmond K, Thun MJ. Overweight, obesity and mortality from cancer in prospectively studied cohort of U.S. adults. N Engl J Med 2003; 348: 1625-38. [CrossRef]

5. Iseri A, Arslan N. Obesity in adults in Turkey: age and regional effects. Eur J Public Health 2009; 19: 91-4. [CrossRef]

6. Scribner DR Jr, Walker JL, Johnson GA, McMeekin SD, Gold MA, Mannel RS. Surgical management of early-stage EC in the elderly: is laparoscopy feasible? Gynecol Oncol 2001; 83: 563-8. [CrossRef]

7. Obermair A, Manolitsas TP, Leung Y, Hammond IG, McCartney AJ. Total laparoscopic hysterectomy versus total abdominal hysterectomy for obese women with EC. Int J Gynaecol Cancer 2005; 15 : 319-24. [CrossRef]

8. Eltabbakh GH, Shamonki MI, Moody JM, Garafano LL. Hysterectomy for obese women with EC: laparoscopy or laparotomy? Gynecol Oncol 2000; 78: 329-35. [CrossRef] 
9. Farthing A, Chatterjee J, Joglekar-Pai P, Dorney E, Ghaem-Maghami S. Total laparoscopic hysterectomy for early stage EC in obese and morbidly obese women. J Obstet Gynaecol 2012; 32: 580-4. [CrossRef]

10. Helm CW, Arumugam C, Gordinier ME, Metzinger DS, Pan J, Rai SN. Laparoscopic surgery for EC: increasing body mass index does not impact postoperative complications. J Gynecol Oncol 2011; 22: 168-76. [CrossRef]

11. Santi A, Kuhn A, Gyr T, Eberhard M, Johann S, Günthert AR, Mueller MD. Laparoscopy or laparotomy? A comparison of 240 patients with early-stage EC. Surg Endosc 2010; 24: 939-43. [CrossRef]

12. FIGO stages-1988 revision (Announcement). Gynecol Oncol 1989; 135: 125-6.

13. Garry R, Reich H, Liu CY. Laparoscopic hysterectomy-definitions and indications. Gynaecol Endosc 1994; 3: 1-3.

14. Trentham-Dietz A, Nichols HB, Hampton JM, Newcomb PA. Weight change and risk of endometrial cancer. Int J Epidemiol 2006; 35: 151-8. [CrossRef]

15. Weaver JM. Increased anesthetic risk for patients with obesity and obstructive sleep apnea. Anesth Prog 2004; 51: 75.

16. Eisenhauer EL, Wypych KA, Mehrara BJ, Lawson C, Chi DS, Barakat RR, Abu-Rustum NR. Comparing surgical outcomes in obese women undergoing laparotomy, laparoscopy, or laparotomy with panniculectomy for the staging of uterine malignancy. Ann Surg Oncol 2007; 14: 2384-91. [CrossRef]

17. Rock JB, Washington MK, Adsay NV, Greenson JK, Montgomery EA, Robert ME, et al. Debating Deposits: An Interobserver Variability Study of Lymph Nodes and Pericolonic Tumor Deposits in Colonic Adenocarcinoma. Arch Pathol Lab Med 2013; 138: 636-42. [CrossRef]

18. Cormier B, Sauthier P, Lussier C, Zang G, Mayrand MH. Determinants of lymph node count in EC surgical staging. Int $\mathrm{J}$ Gynecol Cancer 2012; 22: 1361-6. [CrossRef]
19. Tozzi R, Malur S, Koehler C, Schneider A. Analysis of morbidity in patients with EC: is there a commitment to offer laparoscopy? Gynecol Oncol 2005; 97: 4-9. [CrossRef]

20. Pellegrino A, Signorelli M, Fruscio R, Villa A, Buda A, Beretta P, et al. Feasibility and morbidity of total laparoscopic radical hysterectomy with or without pelvic limphadenectomy in obese women with stage I EC. Arch Gynecol Obstet 2009; 279: 655-60. [CrossRef]

21. Heinberg EM, Crawford BL, Weitzen SH, Bonilla DJ. Total laparoscopic hysterectomy in obese versus nonobese patients. Obstet Gynecol 2004; 103: 674-80. [CrossRef]

22. Gehrig PA, Cantrell LA, Shafer A, Abaid LN, Mendivil A, Boggess JF. What is the optimal minimally invasive surgical procedure for EC staging in the obese and morbidly obese woman? Gynecol Oncol 2008; 111: 41-5. [CrossRef]

23. Eltabbakh GH, Piver MS, Hempling RE, Recio FO. Laparoscopic surgery in obese women. Obstet Gynecol 1999; 94: 704-8. [CrossRef]

24. Pasic R, Levine RL, Wolf Jr WM. Laparoscopy in morbidly obese patients. J Am Assoc Gynecol Laparosc 1999; 6: 307-12. [CrossRef]

25. Scribner DR Jr, Walker JL, Johnson GA, McMeekin DS, Gold MA, Mannel RS. Laparoscopic pelvic and paraaortic lymph node dissection in the obese. Gynecol Oncol 2002; 84: 426-30. [CrossRef]

26. Manolitsas TP, McCartney AJ. Total laparoscopic hysterectomy in the management of endometrial carcinoma. J Am Assoc Gynecol Laparosc 2002; 9: 54-62. [CrossRef]

27. Caquant $\mathrm{F}$, Mas-Calvet $\mathrm{M}$, Turbelin $\mathrm{C}$, Lesoin A, Lefebvre $\mathrm{D}$, Narducci F. EC by laparoscopy and vaginal approach in the obese patient. Bull Cancer 2006; 93: 402-6.

28. O'Hanlan KA, Lopez L, Dibble SL, Garnier AC, Huang GS, Leuchtenberger $\mathrm{M}$. Total laparoscopic hysterectomy: body mass index and outcomes. Obstet Gynecol 2003; 102: 1384-92. [CrossRef] 